\title{
Avoidable hospitalizations in Switzerland: a small area analysis on regional variation, density of physicians, hospital supply and rurality
}

\author{
Claudia Berlin ${ }^{1}$, André Busato ${ }^{1,2^{\wedge}}$, Thomas Rosemann², Sima Djalali² and Maud Maessen ${ }^{1 *}$
}

\begin{abstract}
Background: Avoidable hospitalizations (AH) are hospital admissions for diseases and conditions that could have been prevented by appropriate ambulatory care. We examine regional variation of AH in Switzerland and the factors that determine $\mathrm{AH}$.

Methods: We used hospital service areas, and data from 2008-2010 hospital discharges in Switzerland to examine regional variation in $\mathrm{AH}$. Age and sex standardized $\mathrm{AH}$ were the outcome variable, and year of admission, primary care physician density, medical specialist density, rurality, hospital bed density and type of hospital reimbursement system were explanatory variables in our multilevel poisson regression.

Results: Regional differences in AH were as high as 12-fold. Poisson regression showed significant increase of all $\mathrm{AH}$ over time. There was a significantly lower rate of all $\mathrm{AH}$ in areas with more primary care physicians. Rates increased in areas with more specialists. Rates of all $\mathrm{AH}$ also increased where the proportion of residences in rural communities increased. Regional hospital capacity and type of hospital reimbursement did not have significant associations. Inconsistent patterns of significant determinants were found for disease specific analyses.

Conclusion: The identification of regions with high and low AH rates is a starting point for future studies on unwarranted medical procedures, and may help to reduce their incidence. AH have complex multifactorial origins and this study demonstrates that rurality and physician density are relevant determinants. The results are helpful to improve the performance of the outpatient sector with emphasis on local context. Rural and urban differences in health care delivery remain a cause of concern in Switzerland.
\end{abstract}

Keywords: Ambulatory care, Health services, Small area variation analysis, Hospitalization

\section{Background}

Increasing utilization and rising health care costs threaten the financial sustainability of many western health care systems. Governments and researchers have a growing interest in identifying ineffective and unnecessary health care. Avoidable hospitalizations (AH), also referred to as hospitalizations for ambulatory care sensitive conditions (ACSC) are hospital admissions for diseases and conditions that might have been avoided if better ambulatory care were available [1]. AH are indicators of access and quality of ambulatory care and have been used to monitor

\footnotetext{
* Correspondence: mmaessen@ispm.unibe.ch

Deceased

'Institute of Social and Preventive Medicine, University of Bern,

Finkenhubelweg 11, 3012 Bern, Switzerland

Full list of author information is available at the end of the article
}

health system performance in several countries, including the United States, Canada, Brazil, several European countries, New Zealand and Australia [2-11]. Comparisons between countries that show $\mathrm{AH}$ rates for different health care systems may point out strengths and weaknesses of each system.

Structural deficits of care provision such as inequitable access across different societal groups, e.g. urban rural differences, racial and ethnic minorities or different levels of health insurance coverage were identified mainly in the US literature as important predictors of AH's [12,13]; but $\mathrm{AH}$ can also be seen as an indicator of process quality resulting in medical procedures not warranted by effective needs [14]. We are in favor of this process based view as it seems to be more relevant for the Swiss health system 
which is characterized by high density of supply and generally unlimited access to care [15].

For Switzerland, comprehensive data on AH in different regions and its causal factors are currently unavailable [11]. Switzerland is an interesting country to study $\mathrm{AH}$, because it spends more on health care per capita (5270 USD) than any other country except the United States (8233 USD) and Norway (5388 USD) [16]. Switzerland is also an OECD country with among the highest per capita availability of physicians and nurses and it has one of the world's highest life expectancies [17].

Health care services in Switzerland are reimbursed by private insurances with compulsory basic health plans that cover a comprehensive catalogue of goods and services for all Swiss inhabitants. There are practically no uninsured patients and limited access to health care is rarely a factor in AH. However, Swiss health care is also characterized by considerable fragmentation due to cantonal autonomy [18] and heterogeneity regarding the distribution of physicians, hospitals and medical facilities, so regional variation of $\mathrm{AH}$ rates is to be expected. This project was initiated by the Swiss Federal Office of Public Health (SFOPH) with the goal of documenting regional variation in $\mathrm{AH}$, and identifying relevant determinants of $\mathrm{AH}$ rates in Switzerland.

\section{Methods}

\section{Design of the study}

The study is designed as a retrospective analysis of all hospitalizations in Switzerland for the years 2008-2010. In 2002, the OECD initiated the Health Care Quality Indicator Project to measure and compare the quality of health care provision across countries and to develop a set of health care quality indicators $[15,19,20]$. Within this framework, the OECD uses $\mathrm{AH}$ as a measure of quality for prevention and management of chronic diseases in primary care. For comparability reasons, these indicators, including hospitalizations with a principal ICD10 code of asthma, chronic obstructive pulmonary disease (COPD), diabetes complications, congestive heart failure (CHF), and hypertension [19], are used to define AH for this study. Based on OECD eligibility criteria, we included only patients aged 15 and up (15+) and patients not transferred from other hospitals. Detailed ICD codes and additional information on inclusion and exclusion criteria of these conditions as defined by the OECD are given in the Additional file 1.

\section{Data}

We used data from multiple sources. Inpatient care data, including patient demographics, regional data of patient residency, characteristics of hospitalizations (length of stay, type of discharge, referral pathways, health insurance status) and diagnostic and treatment data (ICD10, procedure codes and All Patient Diagnosis Related Groups (APDRG's)) were extracted from the "Medizinische Statistik der Krankenhäuser", housed at the Swiss Federal Statistical Office (SFSO) [21]. These data cover all hospitalizations of acute care hospitals in Switzerland. One patient can be hospitalised multiple times (multiple cases). Anonymized unique patient identifiers allow tracking patients across hospitals in case of multiple hospitalizations. Data on structural attributes of acute care hospitals (localization, type, size and specialization of hospitals) are also available from the SFSO (Krankenhausstatistik).

Demographic data at the community level, including age and gender distribution, were available from the SFSO (census data) [22]. In 2010, a new federal population census was introduced by the SFSO (SHAPE project) and the population aged $15+$ was used to build the denominator to calculate regional rates of AH for 2010. SHAPE data were also used to directly standardize rates by sex and age groups.

\section{Geographic unit}

Utilization-based health service areas (HSA) of acute care hospitals were the unit of geographic analyses. HSA's were constructed by analysing discharge data of all acute care hospitals in Switzerland for the period of 2008-2010 [23,24]. We used HSA's and aggregated zipcode areas of patient residence as the smallest geographic unit (MedStat areas). HSA's were constructed by crosstabulating the sum of discharges of every zip-code cluster with all possible hospital regions, and then these regions were merged into an HSA by assigning to the hospital region in which the highest number of patients were treated [25]. Using HSA's has the advantage of describing where patients actually receive care, without regard to cantonal or other administrative borders [21,23,24,26,27]. This approach is well established and has become an indispensable source of information for current US healthcare reformers [28].

In 2008, the SFSO modified the concept of MedStat areas to make them compatible with other geographic classification systems. However, these changes were not equally implemented in the data collection procedures of all Swiss cantons during the course of the study. In consequence, geographic classification of hospitals and of patient residence was inconsistent in some cantons. Data from cantons Appenzell Innerrhoden, Appenzell Ausserrhoden, Schaffhausen, St. Gallen, Thurgau and Zurich were therefore discarded from the small area analysis.

\section{Statistical procedures}

All hospitalizations corresponding to the list of $\mathrm{AH}$ published by the OECD were included [15]. Statistical analysis of the data was performed in two steps. The first included 
a descriptive nationwide analysis of $\mathrm{AH}$; the second step identified determinants of regional differences of AH-rates in cantons with eligible data. Descriptive procedures documented overall rates, demographic characteristics, comorbid conditions of patients (Charlson index [29]), length of stay, APDRG cost-weights, and inpatient mortality of all AH in Switzerland. APDRG cost weights that accounted for outliers of length of stay were calculated according to version 6.0 of the specifications of APDRG-Suisse [30].

Regional rates of $\mathrm{AH}$ were calculated at the level of zip-code clusters; the number of $\mathrm{AH}$ admittances in the numerator and the total regional population aged $15+$ were the denominator. Direct standardization of rates by sex and age was performed at the level of zip-code clusters and used the total $15+$ Swiss population of 2010 as the reference.

For geographic analyses we summarized the data at two levels (utilization-based health service areas $[n=59]$ and aggregated zip-code clusters $[n=436]$ ) and developed statistical models to explore the relationship between rates of $\mathrm{AH}$ and characteristics of regional supply of medical care. For each zip code cluster, we determined the density of primary care physicians and of specialists in own practice (physicians per 10000 population). Physician groups were defined based on definitions established by the Swiss Medical association [31]. We also calculated the proportion of the population living in rural communities [32]. At the level of HSA's we calculated the number of acute care hospital beds per 10000 people as a measure of regional hospital supply.

We used a multilevel poisson regression model with the natural logarithm of the age and sex standardized number of $\mathrm{AH}$ as the outcome. We used the log number of the population of zip-code clusters as a fixed offset term in the regression equation. We added information on regional supply of ambulatory care and of population characteristics at the level of zip-code clusters, and added predictors at the level of HSA to estimate effects related to hospital supply. The final set of explanatory variables was obtained after a series of preliminary analyses that explored bivariate associations between the outcome and various measures of physician's supply, including full time equivalents, and other methods to classify patient residency geographically. We eventually included explanatory variables which explained the largest variability of $\mathrm{AH}$ admissions.

These are the explanatory variables included in the final model:

Level 1 (436 zip code areas)

- Year (2008, 2009, 2010)

- Number of primary care physicians per 10000 population
- Number of specialists per 10000 population (all medical specialists with office based practice)

- Proportion of the population living in rural areas

- Type of hospital reimbursement system (APDRG vs. other systems)

Level 2 (59 utilization based health service areas)

- Number of hospital beds per 10000 population

We added random intercepts at the level of HSA's and zip-code clusters to allow for unexplained variation around the respective means. We used the same model to analyse effects associated with the overall rate, and for condition specific rates of AH's. In order to explore linear relationships between continuous explanatory variables and $\mathrm{AH}$, we additionally defined a second model and replaced the continuous data with quintiles of the respective variables. Differences to the first quintile were documented as incidence risk ratios. SAS 9.3 (proc GLIMMIX) was used for multilevel modeling and ArcGis 10 to create maps, the level of significance was set to $\mathrm{p}<0.05$ throughout the study.

\section{Results}

\section{Characteristics of avoidable hospitalizations}

For 2008-2010, 3470812 hospitalizations of patients were documented in the discharge data of the "Medizinische Statistik der Krankenhäuser". Of these, 92804 hospitalizations fulfilled the OECD inclusion criteria and had an ICD10 diagnose that corresponded with a AH. The overall rate of $\mathrm{AH}$ for the $15+$ population during this period was 467 hospitalizations per 100000 . The respective rates were 455 for women and 483 for men. From 2008 to 2010, we observed an increase of 2.7\%. Annual rates for 2008-2010 were 463, 467 and 476 per 100000. In 2010, AH accounted for $3.1 \%$ of all hospital stays $(n=31805)$ and generated 180-200 Mio CHF of direct hospital costs (depending on annual cantonal APDRG base rates). The proportion of patients with additional health insurance in the study population was $15.2 \%$ - slightly below the Swiss average of $16.6 \%$ of all hospitalized patients. $74.3 \%$ of the $\mathrm{AH}$ were classified as emergencies, i.e. with a need for treatment within 12 hours, and $11.8 \%$ of patients were re-hospitalized within 3 months. On average, patients with a rehospitalization had 2.7 hospitalizations during the study period (2.3 for hypertension, 2.6 for Asthma, CHF and Diabetes and 3.0 for COPD). Inpatient mortality of $\mathrm{AH}$ was $5.1 \%$. Characteristics of disease specific $\mathrm{AH}$ are given in Table 1.

\section{Hospital characteristics}

We used the specification of the SFSO to categorize hospitals into five hospital groups based on annual number of all hospitalizations. Characteristics of $\mathrm{AH}$ across these groups are given in Table 2. It is important to note the differences between low-volume clinics, usually located in 
Table 1 Major characteristics of avoidable hospitalizations across ICD10 groups in Switzerland 2008-2010

\begin{tabular}{lllllll}
\hline ICD10 Group & Rate $^{*}$ & $\begin{array}{l}\text { Avg. age of } \\
\text { patients }\end{array}$ & $\begin{array}{l}\text { Avg. length of } \\
\text { stay (days) }\end{array}$ & $\begin{array}{l}\text { Emergency } \\
\text { admissions }\end{array}$ & $\begin{array}{l}\text { In-hospital } \\
\text { deaths }\end{array}$ & $\begin{array}{l}\text { 3-month } \\
\text { Rehospitalization }\end{array}$ \\
\hline Asthma & 18.6 & 54.1 & 6.8 & $84.0 \%$ & $0.5 \%$ & $5.6 \%$ \\
$\mathrm{CHF}^{\dagger}$ & 211.0 & 78.8 & 12.2 & $78.1 \%$ & $9.0 \%$ & $11.5 \%$ \\
COPD $^{\ddagger}$ & 110.0 & 71.3 & 11.3 & $73.7 \%$ & $3.6 \%$ & $14.9 \%$ \\
Diabetes & 70.7 & 62.6 & 12.2 & 6.3 & $1.0 \%$ & $7.5 \%$ \\
Hypertension & 58.3 & 70.1 & 11.0 & $71.4 \%$ & $0.4 \%$ & $3.5 \%$ \\
All Avoidable hospitalizations & 468.6 & 72.5 & $74.3 \%$ & $5.1 \%$ & $10.4 \%$ \\
\hline
\end{tabular}

Rate per 100000 total population.

${ }^{\dagger}$ Congestive heart failure.

${ }^{\ddagger}$ Chronic obstructive pulmonary disease.

${ }^{5}$ Percentage of patient rehospitalized within 3 months after the initial hospitalization.

peripheral areas, and high volume clinics, located in urban areas. There was almost twice the proportion of $\mathrm{AH}$ in low-volume clinics ( $4 \%$ vs. $2 \%$ ); average length of stay was six days longer; patients were older; and, in-hospital mortality was higher. In high volume clinics, APDRG cost-weights per case were almost double those of low volume clinics.

\section{Regional differences}

The 59 HSA's included in the study covered $87.0 \%$ of the area of Switzerland and $69.2 \%$ of the Swiss population in 2010. Key characteristics of these areas are given in Table 3. Depending on year, we observed up to 12 -fold regional differences of age and sex standardized rates of $\mathrm{AH}$ across HSA's. As an example, geographic patterns are documented for 2010 in Figure 1. The three year averages of AH rates of HSA's showed only a 3.6-fold regional variation (range: 274-982 admittances per 100000 population). Rate ratios to the mean of the three year averages were used to document the regional variation of $\mathrm{AH}$ across disease groups (Figure 2). This data implies particularly high levels of variation for asthma and hypertension and less variation for congestive heart failure, COPD and diabetes.

The results of multilevel modelling are summarized in Table 4. The data show a significant increase in all $\mathrm{AH}$ over time, and significantly lower rates for all $\mathrm{AH}$ areas with more primary care physicians. Rates were increased in areas with more specialists, and also increased rates in areas with a higher proportion of rural residents. There was an insignificant association of all $\mathrm{AH}$ for regional hospital capacity (hospital beds per 10000 population) and for type of hospital reimbursement (APDRG vs. other). Quintiles of supply and population data show a 0.91 times lower incidence of $\mathrm{AH}$ in areas with more than 8.1 primary care physicians per 10000 compared to areas with less than 3.8 physicians $(\mathrm{p}<0.05)$; there was a 1.15 times higher incidence in areas with more than 4.2 specialists in comparison to areas with zero specialists $(\mathrm{p}<0.05)$ and a 1.12 times greater incidence in areas where more than $42 \%$ of the population lived in rural communities (reference: areas with zero rural residents, $\mathrm{p}<0.05$ ) (Table 4).

Inconsistent patterns of significant incidence ratios across different disease groups were observed for regional care supply. For asthma, a higher number of primary care physicians was partially associated with fewer $\mathrm{AH}$, but increased rates of $\mathrm{AH}$ were observed for diabetic patients in areas with more primary care physicians. We observed more consistent significant associations of $\mathrm{AH}$ with regional specialist supply; higher supply was associated with higher rates irrespective of disease group. Inconsistent and

Table 2 Characteristics of avoidable hospitalizations across different acute care hospital groups

\begin{tabular}{|c|c|c|c|c|c|c|c|}
\hline Hospital group ${ }^{*}$ & $\begin{array}{l}\% \text { avoidable } \\
\text { hospitalizations }{ }^{\dagger} \\
(\%)\end{array}$ & $\begin{array}{l}\text { Patient } \\
\text { age } \\
\text { (mean) }\end{array}$ & $\begin{array}{l}\begin{array}{l}\text { Length } \\
\text { of stay } \\
\text { (days) }\end{array} \\
\end{array}$ & $\begin{array}{l}\text { Charlson } \\
\text { index } \\
\text { (mean) }\end{array}$ & $\begin{array}{l}\text { Cost } \\
\text { weights } \\
\text { (mean) }\end{array}$ & $\begin{array}{l}\text { 3-month } \\
\text { Rehospitalization } \\
(\%)\end{array}$ & $\begin{array}{l}\text { In-hospital } \\
\text { Mortality } \\
(\%) \\
\end{array}$ \\
\hline $\begin{array}{l}\text { Centrally provided treatments } 1 \\
\left(>30^{\prime} 000 \text { admittances/year) }\right.\end{array}$ & 2.1 & 68.2 & 10.5 & 0.23 & 2.33 & $9.8 \%$ & $4.1 \%$ \\
\hline $\begin{array}{l}\text { Centrally provided treatments } 2 \\
\left(9^{\prime} 000-30^{\prime} 000 \text { admittances/year) }\right.\end{array}$ & 2.9 & 73.0 & 10.6 & 0.29 & 1.12 & $9.8 \%$ & $5.5 \%$ \\
\hline Basic care 1 (6'000-9'000 admittances/year) & 3.0 & 70.8 & 10.0 & 0.31 & 1.14 & $9.4 \%$ & $5.1 \%$ \\
\hline Basic care 2 (3'000-6'000 admittances/year) & 2.2 & 70.4 & 10.8 & 0.21 & 1.29 & $10.0 \%$ & $4.2 \%$ \\
\hline Basic care 3 (<3000 admittances/year) & 4.0 & 74.0 & 16.8 & 0.20 & 1.26 & $13.2 \%$ & $6.3 \%$ \\
\hline
\end{tabular}

"Based on definitions of the Swiss Federal Statistical office.

${ }^{\dagger}$ Proportion of avoidable hospitalizations among all hospitalizations.

${ }^{\ddagger}$ Average APDRG cost weights per avoidable hospitalization. 
Table 3 Regional variation, characteristics of 59 health service areas (averages of 2008-2010)

\begin{tabular}{|c|c|c|c|c|}
\hline Characteristic & Average & Min & Max & HILO ratio ${ }^{\ddagger}$ \\
\hline Population size & 94301 & 1614 & 507789 & 314.6 \\
\hline Population density ${ }^{*}$ & 303.4 & 26.4 & 1863.0 & 70.6 \\
\hline Number of hospitals & 2.4 & 1 & 12 & 12.0 \\
\hline Hospital beds per 10000 & 41.1 & 13.5 & 414.0 & 30.7 \\
\hline $\begin{array}{l}\text { Primary care physicians } \\
\text { per } 10000\end{array}$ & 6.5 & 1.9 & 10.9 & 5.7 \\
\hline Specialists per 10000 & 2.1 & 0.0 & 6.2 & $?$ \\
\hline \multicolumn{5}{|l|}{$\begin{array}{l}\text {-Rate of avoidable } \\
\text { hospitalizations }^{\dagger}\end{array}$} \\
\hline - Asthma & 21.5 & 2.2 & 79.5 & 36.1 \\
\hline - congestive heart failure & 236.2 & 146.0 & 569.2 & 3.9 \\
\hline - COPD & 122.0 & 55.4 & 252.9 & 4.6 \\
\hline - Diabetes & 74.1 & 30.4 & 136.3 & 4.5 \\
\hline - Hypertension & 59.9 & 18.4 & 207.0 & 11.3 \\
\hline - all ICD10 groups & 495.2 & 274.5 & 982.4 & 3.6 \\
\hline
\end{tabular}

"Population per $\mathrm{km}^{2}$ surface below 2000 meters altitude.

${ }^{\dagger}$ Age and sex standardized rate per 100000 population.

${ }^{\ddagger}$ Ratio of highest vs. lowest values.

partially non-linear relationships across disease groups were also seen for significant associations of $\mathrm{AH}$ with more rural populations (Table 4).

\section{Discussion}

Our study highlights up to 12-fold regional differences of $\mathrm{AH}$ over a period of three years. Research on medical practice variation shows that regional differences of this extent are mainly associated with the medical care system including provider factors and less to regional variation in the incidence of the underlying disease categories [8,9,33]. Comparative data across countries for avoidable hospitalizations are available from the OECD for Asthma, COPD and uncontrolled diabetes [17]. These data show low overall rates of avoidable hospitalizations for all three conditions in Switzerland implying a high quality of primary care. However, patterns of variation observed in our data point to difficulties of the Swiss health system to provide effective and equitable medical care to all societal groups.

Theoretically, hospital admissions for ACSC can be prevented by effective ambulatory care, irrespective of disease prevalence. However in practice, even the best ambulatory care may not be able to prevent these hospitalizations. Some factors are beyond the scope of ambulatory care providers, for example: different propensity of patients to seek care; advanced stage and complexity of some conditions; lack of compliance with preventive measures; financial constraints; and, poor access to transportation. To some degree, regional differences of $\mathrm{AH}$ rates will continue to reflect differences in prevalence of the underlying disease. However, studies which took regional variation of health status into account still found an independent association between $\mathrm{AH}$ and care supply $[34,35]$. It is therefore unlikely that adjacent geographical areas have a high enough difference in prevalence to produce up to 12-fold regional differences of $\mathrm{AH}$. Our results also showed that, irrespective of condition, the majority of

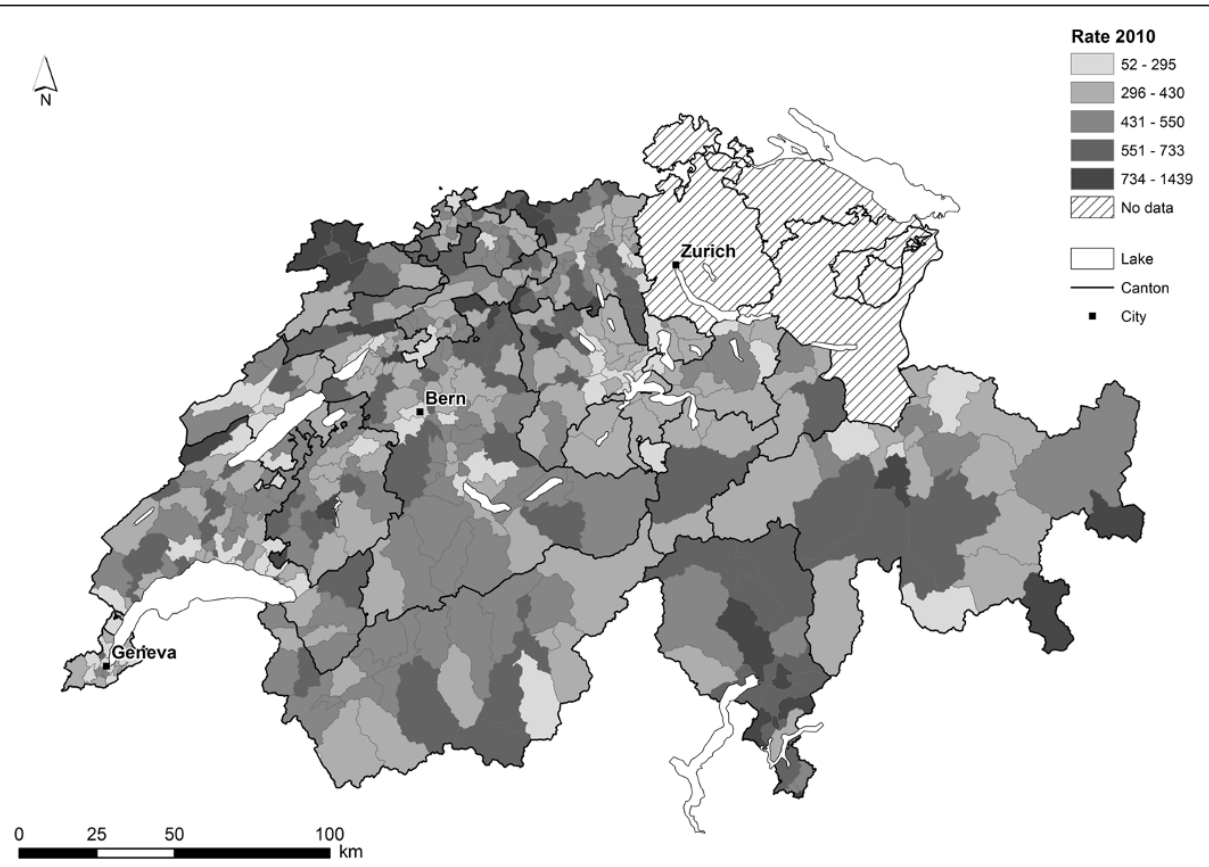

Figure 1 Age and sex standardized rates per 100000 inhabitants of avoidable hospitalizations for 2010 of 436 zip-code clusters. 


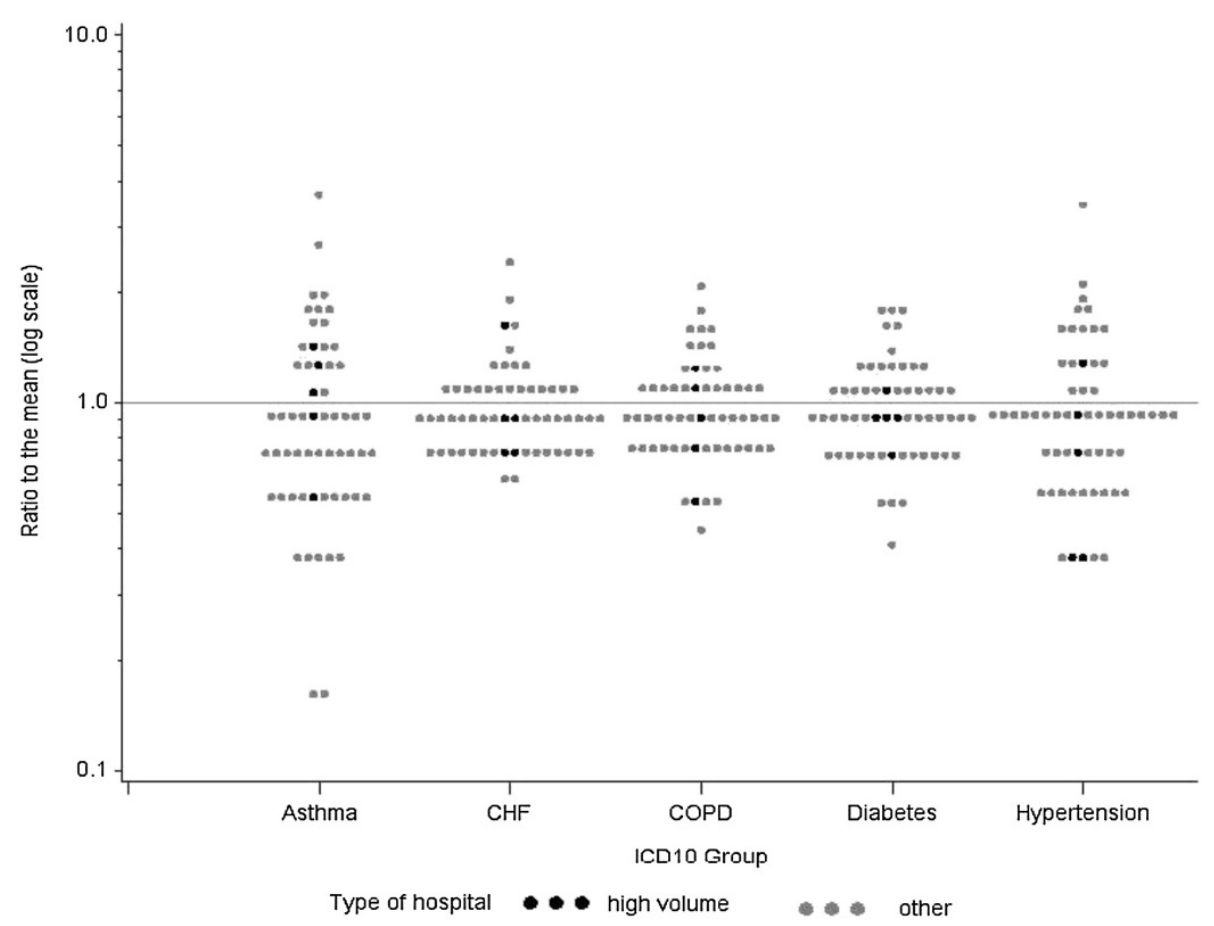

Figure 2 Regional variation (59 HSA's) of disease specific avoidable hospitalization rates*. *Each dot represents a HSA, rates are plotted as a ratio to the mean on a log scale. black dots denote HSA's with at least on high volume clinic.

$\mathrm{AH}$ were categorized as emergencies. These findings may raise questions about how avoidable these hospitalizations are, but they may also suggest inappropriate use of costly emergency services and indicate non-optimal quality and efficacy of outpatient care in Switzerland. Our data allow no further analysis of potential causes of emergency admissions as the data obtained from the Federal Statistical Office contain no variables on type of physicians referring patients to a hospital.

\section{Characteristics of supply}

Regional variation in the data suggest distinct differences between the decisions of primary care physicians and specialists to admit patients to hospitals, even demographic characteristics of patients and higher rates of $\mathrm{AH}$ in predominantly rural populations are both accounted for. An explanation of the patterns would require further comparison of physician practice styles. Risk ratios show that patients living in areas with a high density of primary care physicians are less likely to be admitted to hospitals for conditions that can be treated in ambulatory care. But it is important to note that we observed mostly non-linear relationships between $\mathrm{AH}$ and primary care supply. Our results show that AH can only be reduced in areas with very high density of primary care physicians. We also found differences across major disease groups indicating that primary care physicians may have varying ability to treat health problems and to prevent exacerbations, depending on the conditions they treat.

Our general findings are consistent with multiple studies performed in many countries, with a variety of health care delivery systems [35-37]. The data highlight the importance of primary care as an effective first-contact access to health care irrespective of the characteristics of the health system in which care takes place.

In contrast to the data on primary care physicians, we observed a consistent pattern of higher risks of $\mathrm{AH}$ in areas with a high density of specialists who work in own practices. Specialist practices in Switzerland are almost exclusively located near hospitals (not shown). We cannot confirm other research that established an association between $\mathrm{AH}$ and regional hospital beds supply [38]. Our findings suggest that primary care physicians and specialists have different priorities when they refer patients to hospitals, irrespective of regional hospital capacity.

It may be that specialists are treating more patients with more severe conditions which are more likely to require hospitalization. Our analyses, however, used age and sex standardized population-based rates on a small area scale as an outcome, and it is unlikely that populations in areas with high specialist density are characterized by a higher burden of disease. Specialists working in own practice are often affiliated with local hospitals 
Table 4 Incidence rate ratios of health system characteristics associated with avoidable hospitalizations

\begin{tabular}{|c|c|c|c|c|c|c|}
\hline Characteristic & All avoidable hospitalizations & Asthma & $\mathrm{CHF}$ & COPD & Diabetes & Hypertension \\
\hline Intercept & $0.005^{*}$ & $0.000^{*}$ & $0.002^{*}$ & $0.001^{*}$ & $0.001^{*}$ & $0.001^{*}$ \\
\hline Year $2008^{\dagger}$ & - & - & - & - & - & - \\
\hline Year 2009 & $1.155^{*}$ & 0.979 & $0.923^{*}$ & 1.011 & 0.954 & $1.066^{*}$ \\
\hline Year 2010 & $1.168^{*}$ & $1.105^{*}$ & $0.940^{*}$ & $1.042^{*}$ & $0.904^{*}$ & 1.016 \\
\hline Primary care physicians per 10000 & $0.986^{*}$ & 0.989 & 0.998 & 1.006 & $1.015^{*}$ & 1.003 \\
\hline $\mathrm{Q} 1^{\ddagger}$ & - & - & - & - & - & - \\
\hline Q2 & 1.033 & $0.827^{*}$ & 1.060 & 1.043 & $1.174^{*}$ & 1.064 \\
\hline Q3 & 1.028 & $0.819^{*}$ & 0.996 & 1.049 & $1.152^{*}$ & 1.043 \\
\hline Q4 & 1.043 & $0.769^{*}$ & 1.021 & 1.046 & $1.132^{*}$ & 1.065 \\
\hline Q5 & $0.905^{*}$ & 0.883 & 1.002 & 1.029 & $1.189^{*}$ & 1.020 \\
\hline Specialists per 10000 & $1.017^{*}$ & $1.048^{*}$ & $1.017^{*}$ & $1.017^{*}$ & $1.019^{*}$ & 1.013 \\
\hline $\mathrm{Q}^{\ddagger}{ }^{\ddagger}$ & - & - & - & - & - & - \\
\hline Q2 & 1.019 & 1.162 & 0.961 & 0.996 & 1.073 & 1.018 \\
\hline Q3 & $1.066^{*}$ & 1.044 & 1.008 & 1.031 & $1.126^{*}$ & 0.985 \\
\hline Q4 & $1.067^{*}$ & $1.262^{*}$ & 1.040 & $1.101^{*}$ & 1.063 & 1.005 \\
\hline Q5 & $1.152^{*}$ & $1.330^{*}$ & $1.132^{*}$ & $1.125^{*}$ & $1.162^{*}$ & 1.131 \\
\hline Proportion of residents in rural communities & $1.113^{*}$ & 0.799 & $1.207^{*}$ & 1.061 & 0.981 & 0.888 \\
\hline $\mathrm{Q} 1^{\ddagger}$ & - & - & - & - & - & - \\
\hline Q2 & 0.987 & 0.918 & 1.023 & $0.895^{*}$ & 0.999 & 0.887 \\
\hline Q3 & 1.038 & 0.842 & 1.044 & $1.148^{*}$ & 0.990 & 0.967 \\
\hline Q4 & 1.037 & $0.771^{*}$ & 1.047 & 1.006 & 1.055 & 0.972 \\
\hline Q5 & $1.115^{*}$ & 0.859 & $1.171^{*}$ & 1.022 & 1.009 & 0.897 \\
\hline Hospital beds per 10000 & 1.000 & 1.001 & 0.999 & 1.001 & 1.000 & 0.998 \\
\hline $\mathrm{Q} 1^{\ddagger}$ & - & - & - & - & - & - \\
\hline Q2 & 1.008 & 1.144 & 1.040 & 0.959 & 1.134 & 0.918 \\
\hline Q3 & 1.023 & 1.076 & 1.027 & 1.069 & 1.141 & $0.804^{*}$ \\
\hline Q4 & 1.026 & 1.023 & 1.032 & 1.073 & 1.141 & $0.838^{*}$ \\
\hline Q5 & 1.024 & 1.062 & 1.001 & 1.069 & 1.070 & 0.877 \\
\hline Type of hospital reimbursement & 0.949 & $1.414^{*}$ & 1.005 & 0.909 & 0.932 & $0.662^{*}$ \\
\hline
\end{tabular}

* Significant incidence risk ratio, $\mathrm{p}<0.05$

${ }^{\dagger}$ Year 2008 as the reference.

${ }^{\ddagger}$ Incidence risk ratio from a model with annual quintiles of continuous explanatory variables with the first quintile as the reference, quintiles are varying across years therefore no threshold levels are given in the table.

and, to some degree, hospital admissions may be influenced by financial incentives [39].

We observed distinct differences between patient characteristics and outcome indicators for high- and low volume clinics. AH in low-volume clinics were characterized by older patients with fewer comorbid conditions, higher 3-month rehospitalization rates, and higher in-patient mortality. These results appear contradictory and raise questions about the validity of diagnostic data; it is unlikely that older patients have lower burden of disease and fewer comorbid conditions. We speculate that this may be explained by different procedures for coding diagnoses across hospitals. Larger hospitals usually have dedicated staff for his task, while coding in smaller hospitals is normally done by clinicians.

Hospital data also show higher proportions of $\mathrm{AH}$ and considerable longer hospital stays in low volume clinics. Consistent with our geographic analysis of rurality, and with other research [40], these results suggest potential effects scarcity of outpatient resources in proximity to low-volume clinics. However, we cannot exclude in this setting that supply sensitive effects of such hospitals are also promoting $\mathrm{AH}$ in order to legitimate the viability of low-volume hospitals. Due to lack of data, we cannot discriminate between the two mechanisms. 


\section{Patient characteristics}

Our data showed more AH in men and confirmed gender associated differences documented in other research $[20,41]$. Our evidence on the socio-economic status of patients was in conflict with other research $[37,42]$. Some characteristics of Swiss health care are therefore important to note. All Swiss residents are required to purchase compulsory health insurance, covering a comprehensive catalogue of goods and services. Residents may also have supplementary health insurance contracts that typically provide superior levels of accommodation, give more choice of in-hospital physicians in hospitals and may provide cash benefits for sickness absence [18]. Data from the 2007 Swiss health survey shows that supplementary health insurance is typically purchased by those with high income [43]. Type of insurance coverage is thus a good proxy for the socio-economic status of patients. Our data on health insurance status of patients hospitalized for ACSC show 1.4\% less patients with supplementary coverage compared to the overall Swiss average of $16.6 \%$ of patients with supplementary coverage. The results do not support the evidence that $\mathrm{AH}$ is influenced by a socioeconomic gradient in the setting of Swiss health care.

As in previous research $[40,44]$, regional variation in our data indicates positive associations between $\mathrm{AH}$ and rurality of patient residence. Appropriate allocation of resources in rural areas is of concern to health care planners. However, we cannot distinguish between the effects of limited access to care and patient level factors that have been observed among rural residents in previous research, such as lower propensity to seek care [7]. More data is required to explain this regional variation within Swiss health care, and until it is collected and analyzed, specific policy recommendations cannot be made.

\section{Strengths and limitations}

Although we used hierarchical mixed models with random effects at the level of HSA's and zip-code clusters, which should address some concerns about unmeasured variables, it is important to recognize that health care delivery in the out-patient sector is highly complex. Statistical modelling is difficult because factors like physician behaviour, perceptions of quality of the interaction between patients and physicians, social status of patients and cultural norms including differential propensity among subpopulations to seek care are not fully understood [45]. The search for determinants is further complicated by a scarcity of data that measures the impact of different forms of care delivery on patient health at the health system level.

We were also limited by the lack of ambulatory care sensitive conditions specifically validated as indicators of quality of care for Switzerland. When using administrative data it is not always possible to directly discriminate between $\mathrm{AH}$ and necessary hospitalizations. A major limitation is that we have no knowledge about the patient's history of disease before the admission to the hospital: We don't know whether the patient's disease or symptoms of the disease were diagnosed, appropriate treated and monitored by ambulatory care before [1]. So we cannot determine with certainty that the hospitalization was clinically preventable or necessary. Although this misclassification on clinical level is unfortunate, we believe that the AH selection of the OECD can still be useful as a health indicator from a health service perspective.

The concept of avoidable hospitalizations is based on specific diagnoses that should not be treated in hospitals. Database information allows therefore only indirect identification of avoidable hospitalizations. We used the criteria of the OECD initiated Health Care Quality Indicator Project as the case definition of $\mathrm{AH}$, but clinical criteria and appropriateness of hospitalization remains subject of constant debate. It will continue to be, as long as the concept of $\mathrm{AH}$ is not validated by patient-level outcomes. The concept of AH does not take into account the potential benefits for patients of a theoretically avoidable hospital stay. But as long as valid data regarding the outcome of hospitalizations on patient health remain unavailable, $\mathrm{AH}$ is currently the best approach for estimating the appropriateness of care.

We used administrative hospital data not specifically designed for this type of research, which caused a number of problems. Our results indicate that completeness and accuracy of coding diagnoses may differ between hospitals and that accuracy of geographic data of hospital location and patient residence were compromised in some cantons. This forced us to exclude data from six cantons for small area analysis. These difficulties directly reflect effects of federalism and cantonal autonomy in Swiss health care and point to an urgent need to improve the quality of nationwide health data collection.

Finally, we used age and sex standardized rates of AH for the whole population as the outcome in this study. This outcome may underestimate the overall burden of ACSC, and rates adjusted to the underlying disease prevalence should be used instead [46]. Unfortunately, small area data for disease prevalence are not available, and an expensive data collection processes would be required to obtain such data. However regional differences of rates of $\mathrm{AH}$ can also be interpreted as differential ability of a health system to meet region-specific burdens of ACSC; a prevalence adjusted analysis would obliterate such differences.

The major strength of this study is its nationwide approach; it gives insight into $\mathrm{AH}$ rates that transcend cantonal administrative boundaries. It proves that small 
area analysis in a complex setting is feasible, and has opened the door to further monitoring of regional variations of health interventions, which will support evidence-based policy making in Swiss health care. Another strength is our use of OECD definitions for AH and reported disease specific characteristics. This well established approach improves the generalizability of our data and allows comparative analyses across multiple health systems [15].

\section{Conclusions}

We identified significant determinants of $\mathrm{AH}$ in the Swiss health system that are important for health care planning. We uncovered disease specific characteristics of $\mathrm{AH}$, indicating that disease specific health policy may be effective. However, we are limited by the quality of the data we used; more valid data must be collected by hospitals and ambulatory care providers. Our results may be used to improve the performance of the outpatient sector, particularly in local regional contexts. Rural and urban differences remain a cause of concern. Future research should assess specific physician characteristics that contribute to $\mathrm{AH}$, with the goal of reducing the number of unnecessary procedures.

\section{Additional file}

Additional file 1: These tables represent the in- and exclusion criteria for avoidable hospitalizations based of on the criteria from the OECD Health Care Quality Indicator Project.

\section{Abbreviations}

$\mathrm{AH}$ : Avoidable hospitalizations; ACSC: Ambulatory care sensitive conditions; COPD: Chronic obstructive pulmonary disease; CHF: Congestive heart failure; SFOPH: Swiss Federal Office of Public Health; OECD: Organization for economic co-operation and development; SHAPE: System of household and personal statistics; HSA: Health service areas; ICD10: The International Classification of Diseases version 10; APDRG: All patient diagnosis related groups; CHF: Swiss Franc.

\section{Competing interests}

All authors declare that they have no competing interests.

\section{Authors' contributions}

$\mathrm{CB}$ analysed the validity of the geographic data, produced the geographical map and interpreted the results. AB, deceased on $12^{\text {th }}$ November 2013, designed the original study project and performed the data analyses. MM helped drafting the manuscript and interpreting and prioritising the results. All authors contributed to revising the manuscript and approved the final manuscript.

\section{Acknowledgements}

The study was funded by the SFOPH and Prof. Busato partly by the Swiss Medical Association. By contractual agreement, the funding organizations had no influence in study design; in the collection, analysis and interpretation of data; in the writing of the report; and in the decision to submit the article for publication.

\section{Author details}

${ }^{1}$ Institute of Social and Preventive Medicine, University of Bern, Finkenhubelweg 11, 3012 Bern, Switzerland. ${ }^{2}$ Institute of General Practice and Health Services Research, University of Zurich, Pestalozzistrasse 24, 8091 Zurich, Switzerland.
Received: 18 June 2013 Accepted: 18 June 2014

Published: 3 July 2014

\section{References}

1. Caminal J, Starfield B, Sanchez E, Casanova C, Morales M: The role of primary care in preventing ambulatory care sensitive conditions. Eur J Public Health 2004, 14(3):246-251.

2. Ahern MM, Hendryx M: Avoidable hospitalizations for diabetes: comorbidity risks. Dis Manag 2007, 10(6):347-355.

3. Cheng SH, Chen CC, Hou YF: A longitudinal examination of continuity of care and avoidable hospitalization: evidence from a universal coverage health care system. Arch Intern Med 2010, 170(18):1671-1677.

4. Cloutier-Fisher D, Penning MJ, Zheng C, Druyts EB: The devil is in the details: trends in avoidable hospitalization rates by geography in British Columbia, 1990-2000. BMC Health Serv Res 2006, 6:104.

5. Burgdorf F, Sundmacher L: Potentially avoidable hospital admissions in Germany: an analysis of factors influencing rates of ambulatory care sensitive hospitalizations. Dtsch Arztebl Int 2014, 111(13):215-223.

6. Jackson G, Tobias M: Potentially avoidable hospitalisations in New Zealand, 1989-98. Aust N Z J Public Health 2001, 25(3):212-221.

7. Longman JM, Singer JB, Gao Y, Barclay LM, Passey ME, Pirotta JP, Heathcote KE, Ewald DP, Saberi V, Corben P, Morgan GG: Community based service providers' perspectives on frequent and/or avoidable admission of older people with chronic disease in rural NSW: a qualitative study. BMC Health Serv Res 2011, 11:265.

8. Magan P, Otero A, Alberquilla A, Ribera JM: Geographic variations in avoidable hospitalizations in the elderly, in a health system with universal coverage. BMC Health Serv Res 2008, 8:42.

9. Page A, Ambrose S, Glover J, Hetzel D: Atlas of Avoidable Hospitalisations in Australia: Ambulatory Care-Sensitive Conditions. Adelaide: PHIDU, University of Adelaide; 2007.

10. Pappas G, Hadden WC, Kozak LJ, Fisher GF: Potentially avoidable hospitalizations: inequalities in rates between US socioeconomic groups. Am J Public Health 1997, 87(5):811-816.

11. Rosano A, Abo Loha C, Falvo R, van der Zee J, Ricciardi W, Guasticchi G, de Belvis AG: The relationship between avoidable hospitalization and accessibility to primary care: a systematic review. Eur J Public Health 2012.

12. Basu J, Friedman B, Burstin H: Managed care and preventable hospitalization among Medicaid adults. Health Serv Res 2004, 39(3):489-510.

13. Ricketts TC, Randolph R, Howard HA, Pathman D, Carey T: Hospitalization rates as indicators of access to primary care. Health Place 2001, 7(1):27-38.

14. Jankowski R: What do hospital admission rates say about primary care? BMJ 1999, 319(7202):67-68.

15. OECD: Health at a Glance 2011. In OECD Indicators. Paris, France: OECD; 2011.

16. OECD: OECD Health Data 2012 How Does Switzerland Compare. 2012. http://www.oecd.org/els/health-systems/oecdreviewsofhealthsystemsswitzerland.htm.

17. OECD: Health at a Glance 2012. In OECD Indicators. Paris, France: OECD; 2012.

18. OECD/WHO: OECD Reviews of Health Systems: SWITZERLAND 2011. Paris, France: OECD Publishing; 2011.

19. Marshall M, Klazinga N, Leatherman S, Hardy C, Bergmann E, Pisco L, Mattke S, Mainz J: OECD Health Care Quality Indicator Project. The expert panel on primary care prevention and health promotion. Int I Qual Health Care 2006, 18(Suppl 1):21-25.

20. OECD: Health at a Glance 2009. In OECD Indicators. Paris, France: OECD; 2009.

21. Busato A, von Below G: The implementation of DRG based hospital reimbursement in Switzerland: a population based perspective. Health Res Policy Syst 2010, 8:31. Oct 16.

22. Spoerri A, Zwahlen M, Egger M, Bopp M: The Swiss National Cohort: a unique database for national and international researchers. Int J Public Health 2010, 55(4):239-242.

23. Klauss G, Staub L, Widmer M, Busato A: Hospital service areas - a new tool for health care planning in Switzerland. BMC Health Serv Res 2005, 5:33.

24. Widmer M, Matter P, Staub L, Schoeni-Affolter F, Busato A: Regional variation in orthopedic surgery in Switzerland. Health Place 2009, 15(3):761-768. 
25. Dartmouth Medical School. Center for the Evaluative Clinical Sciences: The Dartmouth Atlas of Health Care 1998. In The Dartmouth Atlas of Health Care in the United States. Edited by Wennberg J, Cooper M. Chicago, USA: American Hospital Publishing; 1998.

26. The Dartmouth Institute for Health Policy and Clinical Practice: Glossary Dartmouth Atlas of Health Care. www.dartmouthatlas.org/tools/glossary.aspx.

27. Matter-Walstra K, Widmer M, Busato A: Analysis of patient flows for orthopedic procedures using small area analysis in Switzerland. BMC Health Serv Res 2006, 6:119.

28. Wennberg JE SB, Fisher ES, Skinner J, Weinstein JN: An Agenda for Change Improving Quality and Curbing Health Care Spending: Opportunities for the Congress and the Obama Administration. In A Dartmouth Atlas White Paper. Lebanon, $\mathrm{NH}$ : The Dartmouth Institute for Health Policiy \& Clinical Practice; 2008

29. Sundararajan V, Henderson T, Perry C, Muggivan A, Quan H, Ghali WA: New ICD-10 version of the Charlson comorbidity index predicted in-hospital mortality. J Clin Epidemio/ 2004, 57(12):1288-1294.

30. APDRG-Suisse: Kostengewichte Version 6.0. Ecublens, Switzerland: APDRG Suisse; 2008.

31. Jaccard Ruedin H, Roth M, Bétrisey C, Marzo N, Busato A: Offre et recours aux soins médicaux ambulatoires en Suisse. In Document de travail 22. Neuchatel, Switzerland: Schweizerisches Gesundheitsobservatorium; 2007. http://www.obsan.admin.ch/bfs/obsan/de/index/01/02.html? publication $\mid \mathrm{D}=2605$.

32. Schuler M, Dessermontet $P$, Joye D: Eidgenössische Volkszählung 2000: Die Raumgliederungen der Schweiz. Neuenburg, Switzerland: Swiss Federal Statistical Office; 2005.

33. Goodman DC, Brownlee S, Chang C, Fisher ES: Regional and Racial Variation in Primary Care and the Quality of Care among Medicare Beneficaries. In A Report of the Dartmouth Atlas Project. Hanover, USA: The Dartmouth Institute for Health Policy and Clinical Practice; 2010:37.

34. Parchman ML, Culler SD: Preventable hospitalizations in primary care shortage areas. An analysis of vulnerable Medicare beneficiaries. Arch Fam Med 1999, 8(6):487-491.

35. Laditka JN, Laditka SB, Probst JC: More may be better: evidence of a negative relationship between physician supply and hospitalization for ambulatory care sensitive conditions. Health Serv Res 2005, 40(4):1148-1166.

36. Dusheiko M, Gravelle H, Martin S, Rice N, Smith PC: Does better disease management in primary care reduce hospital costs? Evidence from English primary care. J Health Econ 2011, 30(5):919-932.

37. Agabiti N, Pirani M, Schifano P, Cesaroni G, Davoli M, Bisanti L, Caranci N, Costa G, Forastiere F, Marinacci C, Russo A, Spadea T, Perucci CA, Italian Study Group on Inequalities in Health Care: Income level and chronic ambulatory care sensitive conditions in adults: a multicity population-based study in Italy. BMC Public Health 2009, 9:457.

38. Schreiber S, Zielinski T: The meaning of ambulatory care sensitive admissions: urban and rural perspectives. J Rural Health 1997, 13(4):276-284

39. Budetti PP, Shortell SM, Waters TM, Alexander JA, Burns LR, Gillies RR, Zuckerman H: Physician and health system integration. Health Aff 2002, 21(1):203-210

40. Chen LW, Zhang W, Sun J, Mueller KJ: The magnitude, variation, and determinants of rural hospital resource utilization associated with hospitalizations due to ambulatory care sensitive conditions. J Public Health Manag Pract 2009, 15(3):216-222.

41. Magan P, Alberquilla A, Otero A, Ribera JM: Hospitalizations for ambulatory care sensitive conditions and quality of primary care: their relation with socioeconomic and health care variables in the Madrid regional health service (Spain). Med Care 2011, 49(1):17-23.

42. Roos LL, Walld R, Uhanova J, Bond R: Physician visits, hospitalizations, and socioeconomic status: ambulatory care sensitive conditions in a canadian setting. Health Serv Res 2005, 40(4):1167-1185.

43. Swiss Federal Statistical Office: Schweizerische Gesundheitsbefragung 2007: Erste Ergebnisse. Neuenburg, Switzerland: Swiss Federal Statistical Office; 2008

44. Ansari Z, Barbetti T, Carson NJ, Auckland MJ, Cicuttini F: The Victorian ambulatory care sensitive conditions study: rural and urban perspectives. Soz Praventivmed 2003, 48(1):33-43.
45. Hossain MM, Laditka JN: Using hospitalization for ambulatory care sensitive conditions to measure access to primary health care: an application of spatial structural equation modeling. Int J Health Geogr 2009, 8:51.

46. Lui CK, Wallace SP: A common denominator: calculating hospitalization rates for ambulatory care-sensitive conditions in California. Prev Chronic Dis 2011, 8(5):A102.

doi:10.1186/1472-6963-14-289

Cite this article as: Berlin et al:: Avoidable hospitalizations in Switzerland: a small area analysis on regional variation, density of physicians, hospital supply and rurality. BMC Health Services Research 2014 14:289.

\section{Submit your next manuscript to BioMed Central and take full advantage of:}

- Convenient online submission

- Thorough peer review

- No space constraints or color figure charges

- Immediate publication on acceptance

- Inclusion in PubMed, CAS, Scopus and Google Scholar

- Research which is freely available for redistribution

Submit your manuscript at www.biomedcentral.com/submit
C) BioMed Central 